\title{
Crustal structure in the northern Fossa Magna region, central Japan, modeled from refraction/wide-angle reflection data
}

\author{
Tetsuya Takeda ${ }^{1 *}$, Hiroshi Sato ${ }^{1}$, Takaya Iwasaki ${ }^{1}$, Nobuhisa Matsuta ${ }^{1}$, Shin'ichi Sakai $^{1}$, Takashi Iidaka ${ }^{1}$, and Aitaro Kato ${ }^{2}$ \\ ${ }^{1}$ Earthquake Research Institute, the University of Tokyo, 1-1-1 Yayoi, Bunkyo-ku, Tokyo 113-0032, Japan \\ ${ }^{2}$ The Institute for Frontier Research on Earth Evolution, Japan Marine Science and Technology Center, \\ 2-15 Natsushima-cho, Yokosuka 237-0061, Japan
}

(Received June 3, 2004; Revised December 30, 2004; Accepted December 30, 2004)

\begin{abstract}
The northern Fossa Magna (NFM) is a back-arc rift basin filled with thick Tertiary sediments, which show strong NW-SE shortening deformation. In the NFM, there exist two major active fault systems, the ItoigawaShizuoka Tectonic Line active fault system (ISTL) and the Western Nagano Basin active fault system (WNB), both of which have great potentials to cause destructive earthquakes. By reanalyzing five sets of refraction/wideangle reflection data, we successfully obtained detailed and consistent models of the crustal structure in the NFM region. It was a very effective modeling procedure to incorporate vicinal seismic reflection data and geologic information. The geometries of the active faults in the NFM region were revealed. The ISTL is east dipping, and the WNB is northwest dipping. The Tertiary sedimentary layer $(<4.0 \mathrm{~km} / \mathrm{sec})$ west and adjacent to the ISTL extends to a depth of 4-5 km. The basement rocks below the Central Uplift Belt (CUB) form a wedge structure, which suggests the westward movement of the CUB basement rocks.
\end{abstract}

Key words: Crustal structure, northern Fossa Magna, refraction/wide-angle reflection data, Itoigawa-Shizuoka Tectonic Line, wedge structure.

\section{Introduction}

The Fossa Magna is a back-arc rift basin formed during the opening of the Sea of Japan in the Miocene, and filled with Tertiary thick sediments. In the northern Fossa Magna (NFM) (Fig. 1), there are two major active fault systems that have great potentials to cause destructive earthquakes. One is the Itoigawa-Shizuoka Tectonic Line active fault system (ISTL), which is situated almost along the west margin. It has a high slip rate of 4-9 mm/year and is one of the most active inland fault systems in the Japan arc (Ikeda et al., 2002). The other is the Western Nagano Basin active fault system (WNB), which is located in the east of the NFM. At this fault system, there is a historical record of large inland earthquake, the 1847 Zenkoji earthquake (M7.4) (Usami, 1979). The Central Uplift Belt (CUB) (Yano, 1989), where Neogene volcanic rocks are exposed in places, is located just east and almost parallel to the WNB (Fig. 1). The NFM has been compressed in a NW-SE direction since the late Pliocene, which is responsible for strong folding of the Tertiary sediments between the ISTL and CUB. Ikeda $\mathrm{et}$ al. (2002) suggest that the Otari-Nakayama fault (ONF), which is situated in nearly parallel with the ISTL, is the former ISTL, and that the fault activity has moved westward to the present location since the Quaternary due to thrust-front migration (Ikeda, 1983).

${ }^{*}$ Present address: Geological Survey of Japan, AIST, Central 7, 1-1-1 Higashi, Tsukuba, Ibaraki 305-8567, Japan.

Copy right(c) The Society of Geomagnetism and Earth, Planetary and Space Sciences (SGEPSS); The Seismological Society of Japan; The Volcanological Society of Japan; The Geodetic Society of Japan; The Japanese Society for Planetary Sciences; TERRAPUB
Sato and Hirata (1998) introduced a model of inversion tectonics (Nakamura, 1992) in order to explain the tectonic history in the NFM, based on a reflection experiment. In brief, the ISTL was originally formed as a normal fault in the Miocene, and was reactivated, since the late Pliocene, as a reverse fault due to a subsequent compressive stress field. Furthermore, Sato et al. (2004) interpreted seismic reflection data involving the geologic information, as part of the multidisciplinary project "Slip and Flow Processes in and below the Seismogenic Region" (e.g. Sagiya et al., 2002; Ogawa et al., 2002). Sato et al. (2004) interpreted the formation and shortening deformation process of the NFM based on inversion tectonics. In their model, the CUB basement rocks move upward along the fault plane of the ISTL.

In this area, several velocity models were derived from refraction/wide-angle reflection experiments as shown in Fig. 2 (Asano et al., 1969b; Ikami et al., 1986; Sakai et al., 1996). However, these models do not explicitly show an evidence of inversion tectonics, partly because they were analyzed by conventional approaches that were inappropriate for a calculation of travel-time in a case of complex structure, and partly because the dataset was insufficient. However, if we use modern analysis technique together with known geologic information, we can reveal more detailed crustal structure beneath the NFM. The previous multiple profiles were independently analyzed so far. However, joint analyses of the multiple profiles should also enhance the resolution of the structure, because the survey lines cross each other. Hence, if we undertake the systematic analysis to all of the data, we can obtain velocity structures with 


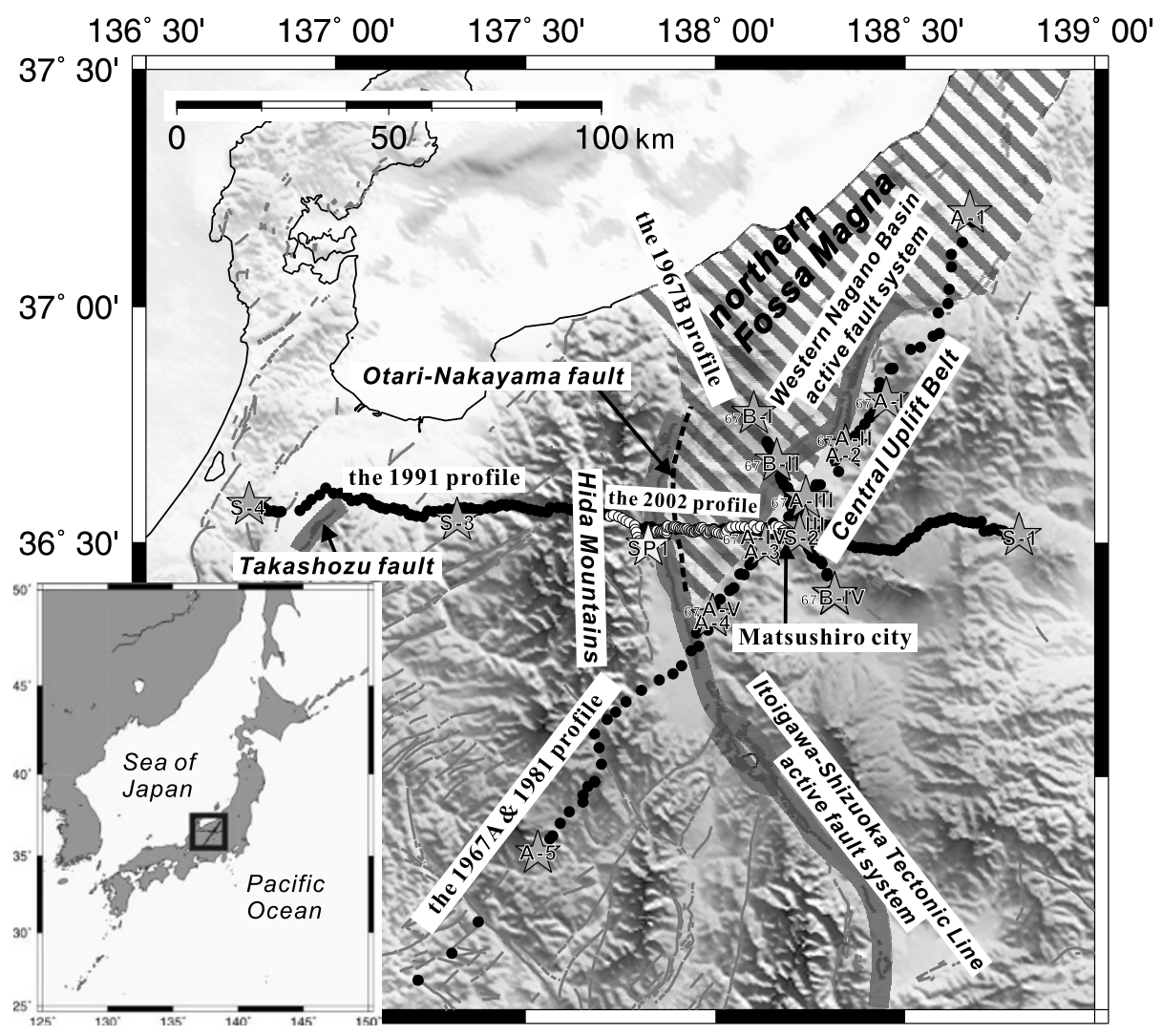

Fig. 1. A location map of the northern Fossa Magna region. The Itoigawa-Shizuoka Tectonic Line active fault system (ISTL) is located north and south bounding the west margin. The Central Uplift Belt (CUB) runs NE-SW. The Western Nagano Basin active fault system (WNB) parallels the CUB. The stars and solid circles indicate the shot points and observation points for the refraction/wide-angle reflection survey, respectively. A dashed line indicates the Otari-Nakayama fault (ONF), which is not presently active (Ikeda et al., 2002).

higher resolution and with more consistency over multiple profiles.

The purpose of this paper, therefore, is to determine detailed and consistent crustal structure models of the entire NFM region derived from refraction/wide-angle reflection data, and to reveal the geometry of the active faults, which is inevitably important to clarify tectonic evolution of the NFM. Additionally, in our modeling, we used the previous reflection results (e.g., Sato and Hirata, 1998; Sato et al., 2004; Ikeda et al., 2004) and geologic information (Geological Survey of Japan, AIST, 2002) as a priori information in order to constrain the model.

\section{Data}

Five sets of refraction/wide-angle reflection data were collected in the NFM region from 1967 to 2002 (Fig. 1). The 1967 experiment, which focused on the area of the 1965 Matsushiro earthquake swarm (Japan Meteorological Agency, 1968), was conducted on two profiles crossing each other (Asano et al., 1969a). The 1981 profile extended the 1967A profile, and passed along the CUB and across the ISTL (Research Group for Explosion Seismology, 1985). The 1991 profile was designed to get a deeper crustal image of the Central Japan (Research Group for Explosion Seismology, 1994). This line crossed our studied area including the CUB, WNB and ISTL with an E-W direction. This experiment, however, had no shot points near the ISTL, which makes difficult to clarify a detailed structure of this active fault system including lateral velocity variation and deep fault geometry.

In 2002 , a reflection survey was performed on $68-\mathrm{km}-$ long NW-SE line located just south of the 1991 profile to image the deep geometry of the ISTL (Sato et al., 2004). One of the shot points of this experiment, SP1, was set quite close to the 1991 profile line. In order to improve a resolution of the structure near the ISTL, we observed this shot by densely spacing receivers $(300-500 \mathrm{~m})$, which were overlapped on the 1991 profile line so as to combine with the 1991 data (Fig. 1, Takeda et al., 2003).

\section{Modeling Procedures}

Using five data sets, we attempted to construct a 2-D $P$ wave velocity structure in each direction by forward modeling. However, we encountered three problems in our modeling procedures. First, inadequate ray coverage generates trade-off between its velocity and thickness of layer, which is an inherent problem of the seismic refraction study mainly based on first arrivals. Second, there exists a problem in relation to the fault structure of the ISTL. If the fault zone is steep and narrow in width, it is difficult to estimate the fault geometry. Third, a structure below the Hida Mountains cannot be obtained because there are very few ray paths. The 1991 profile data strongly indicate an existence of a high attenuation body there.

To solve the first difficulty, we compensated the ray coverage to some extent by the additional data acquisition of 

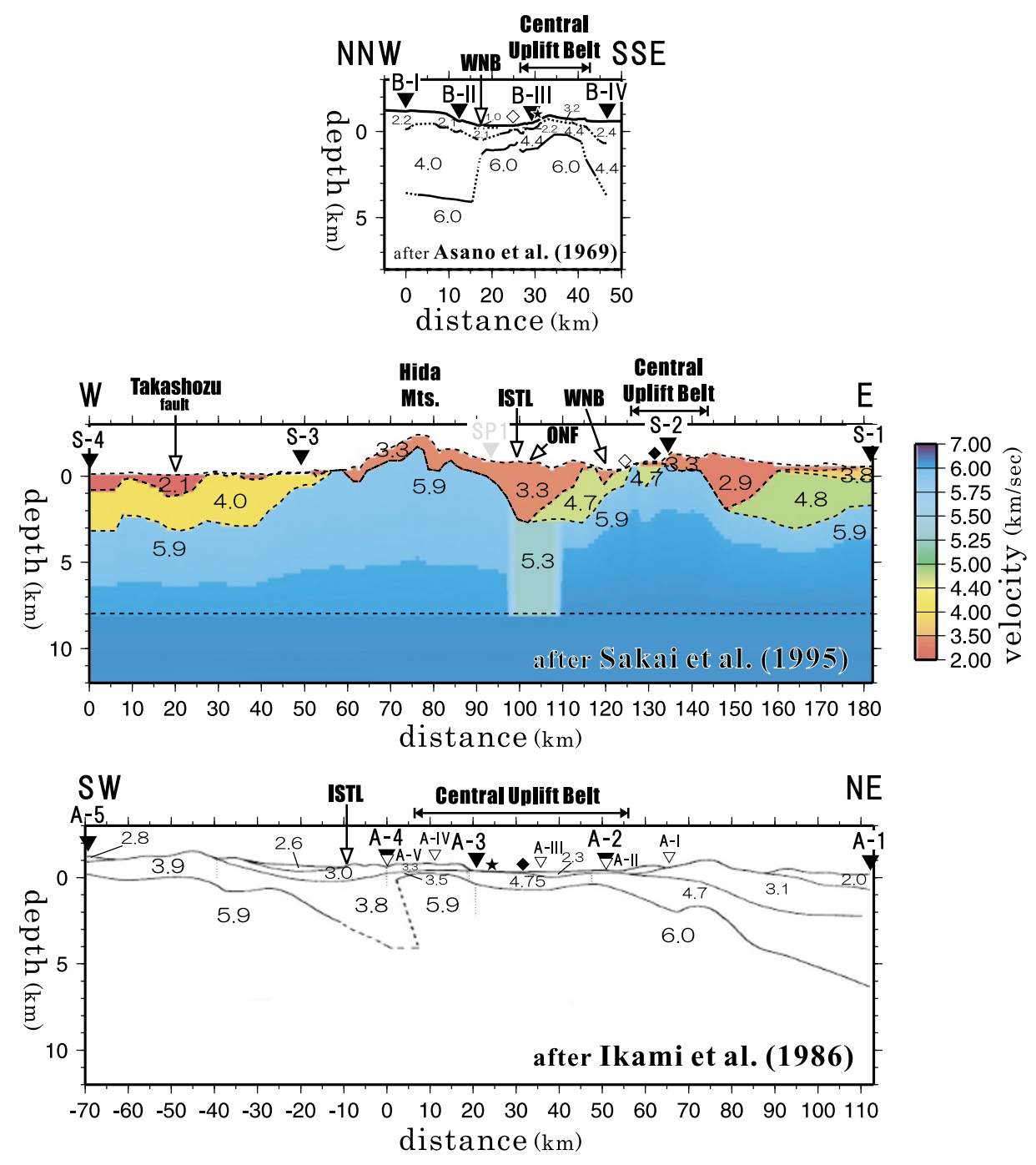

Fig. 2. Velocity structure models for previous studies; (a) the 1967B profile after Asano et al. (1969b), (b) the 1991 profile after Sakai et al. (1996), and (c) the 1981 profile after Ikami et al. (1986).

the 2002 experiment. Additionally, dense data of first arrivals from the previous seismic reflection data (Sato and Hirata, 1998) could be used to constrain the surface velocity. Surface geology (Geological Survey of Japan, AIST, 2002) is also useful information in introducing lateral velocity variation. We inferred the rock type based on the geologic information, and could estimate the velocity by referring to a $P$-wave velocity list of various rocks in Japan, which was compiled by Hattori and Sugimoto (1975a, b).

For the second problem, we incorporated the results of the previous reflection surveys (e.g., Sato and Hirata, 1998; Sato et al., 2004; Ikeda et al., 2004). Namely, the highly reliable fault geometry in the shallow part $(<2 \mathrm{~km}$ in depth) given from the reflection images was introduced into our modeling as a priori information (white solid lines in Fig. 3). This treatment is actually effective because reflection sections provided reliable fault location as a boundary of large velocity contrast. We could also trace the structural boundary between the Tertiary sediments and the basement rocks downward to a depth of $2 \mathrm{~km}$.

The third problem cannot be solved by our seismic data alone. Matsubara et al. (2000) successfully imaged the high attenuation body by a tomography analysis using deep earthquakes ( $>30 \mathrm{~km}$ in depth). Therefore, we incorporated the tomography image into our modeling.

The travel-time and the ray paths were calculated using the program coded by Zelt and Barton (1998), which was based on Vidale's (1990) algorithm and was improved to deal with complex structure such as the ISTL. We established initial models incorporating a priori information as described above. The models were modified until the RMS residuals decreased within at least $0.1 \mathrm{sec}$. The velocity structures for the individual profile lines were constrained to keep consistency at the intersection. Additionally, the geometry of the ISTL to a depth of $2 \mathrm{~km}$ was fixed by the reflection data (white solid lines in Fig. 3). Since all refraction data were systematically reanalyzed using a uniform method, we were able to obtain comprehensive velocity models.

\section{Results}

Figure 3 shows the $P$-wave velocity models obtained in the three profiles. Figures 3(a), 3(b) and 3(c) show the 1967B profile (NNW-SSE), the 1991 and 2002 profile (E- 


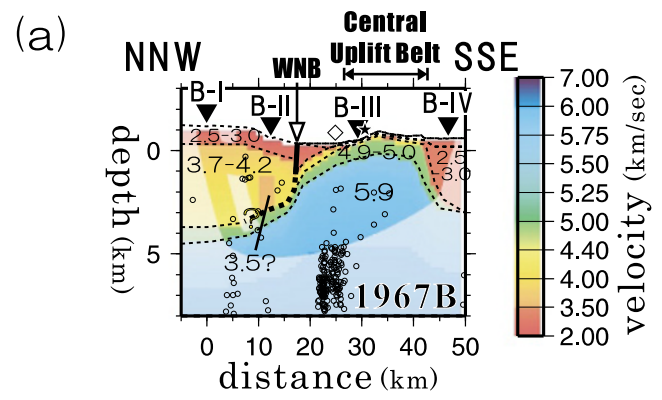

(b)
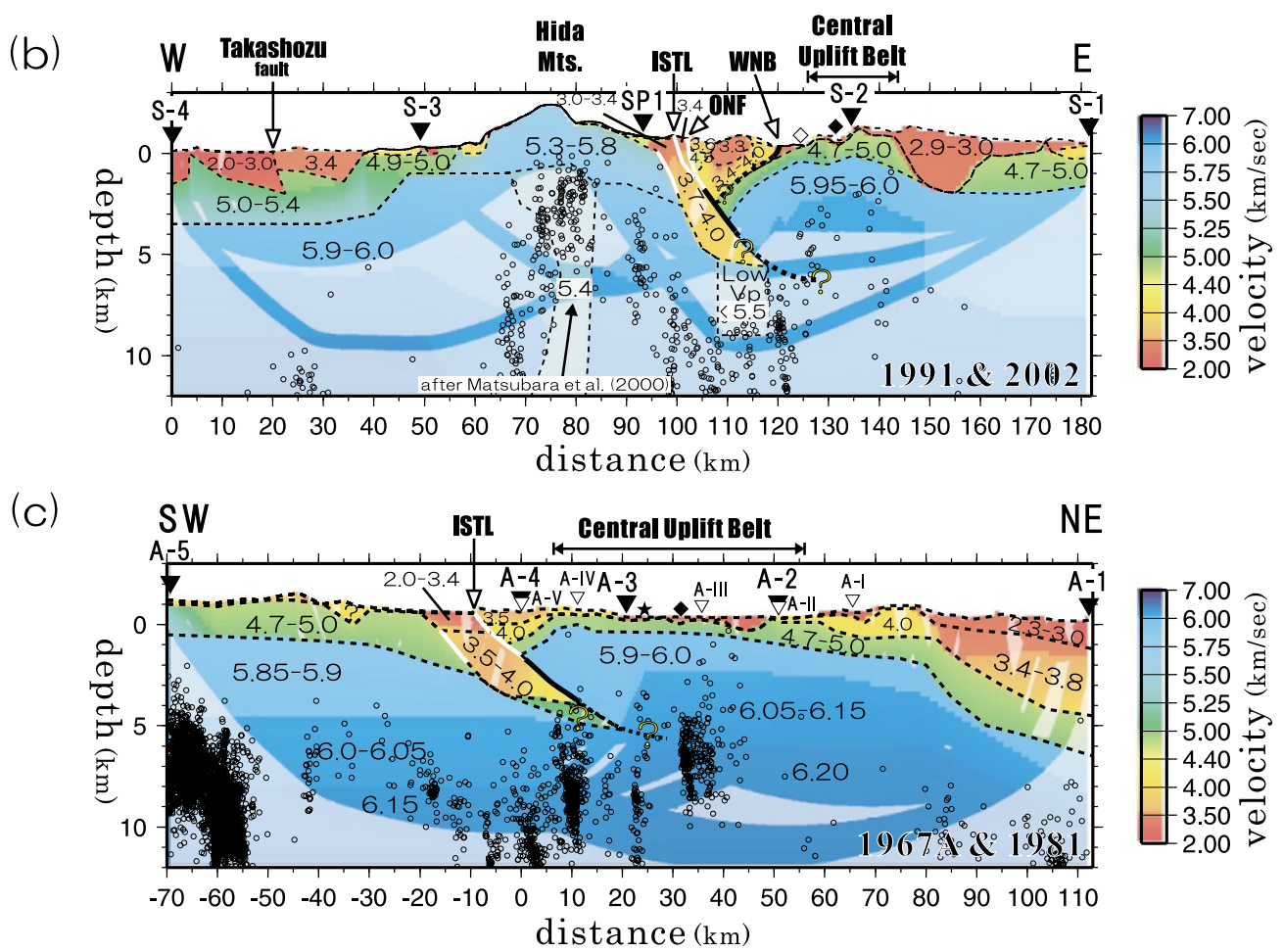

Fig. 3. Velocity structure models from reanalysis of the refraction/wide-angle reflection data. (a) the 1967B profile, (b) the 1991 and 2002 profile, and (c) the 1967A and 1981 profile. The geometries of the ISTL and WNB are highlighted. The white solid lines indicate structural boundaries introduced from reflection images. The solid squares, stars and open squares denote a crossing point with the profile of (a), (b) and (c) respectively. An area without ray paths is shaded. The inverted triangles indicate the shot points. The open circles indicate the hypocenters from 1998-2003, as provided by the Japan Meteorological Agency (JMA). The models are scaled to the same size as those in Fig. 2.

W), and the 1967A and 1981 profile (NE-SW), respectively. In these models, an area without ray paths is shaded because of very low resolution. From the models, it is found that the NFM region is covered with adequate ray paths. In particular, the addition of the 2002 profile data drastically improved resolution beneath the NFM (Fig. 3(b)). Figure 4 shows an example of record sections (SP1), which is superimposed with observed (circle) and calculated (triangle) travel-times. The curves of the observed travel-times show complex undulations, and indicate a remarkable delay in a range of $15-25 \mathrm{~km}$ in distance. The calculated traveltimes are sufficiently consistent with those of the observed. The RMS residual is in a range of $0.08-0.10 \mathrm{sec}$ for all of the profiles. The error of velocity of the sedimentary and the basement rocks were estimated as $0.04-0.4 \mathrm{~km} / \mathrm{sec}$, and $0.03 \mathrm{~km} / \mathrm{sec}$, respectively. The error of uppermost depth of the basement rocks was estimated as $0.3 \mathrm{~km}$.

By incorporating the refraction data, reflection data, and geologic information into our analysis, we were able to successfully construct detailed and consistent crustal models of the entire NFM region. The features of each model are described below.

The 1967(B) profile is shown in Fig. 3(a). At both sides of the CUB, thick sedimentary layers are characteristic. Particularly at the west side, the total thickness of the combined upper and lower sedimentary layers (2.5-3.0 and 3.7$4.2 \mathrm{~km} / \mathrm{sec}$ respectively) exceeds $5 \mathrm{~km}$. The CUB is covered with very thin sedimentary layer $(<0.2 \mathrm{~km})$, underlain by the basement rocks with horst structure. The uplift of the $30 \mathrm{~km}$-wide horst amounts to no less than a 4-km. The velocity of the layer just below the thin sediments was 4.9-5.0 $\mathrm{km} / \mathrm{sec}$, and the layer presumably imply the Neogene volcanic rocks. The velocity of the basement rocks was 5.9 $\mathrm{km} / \mathrm{sec}$. In our model, the WNB is a reverse fault with a northwestward dip extending to a depth of at least $2 \mathrm{~km}$. Although it was difficult to accurately estimate the dip angle, our travel-time data required a northwestward dip of this fault.

The 1991 and 2002 profile is shown in Fig. 3(b). The ray coverage in the deep part is poor because of the seis- 


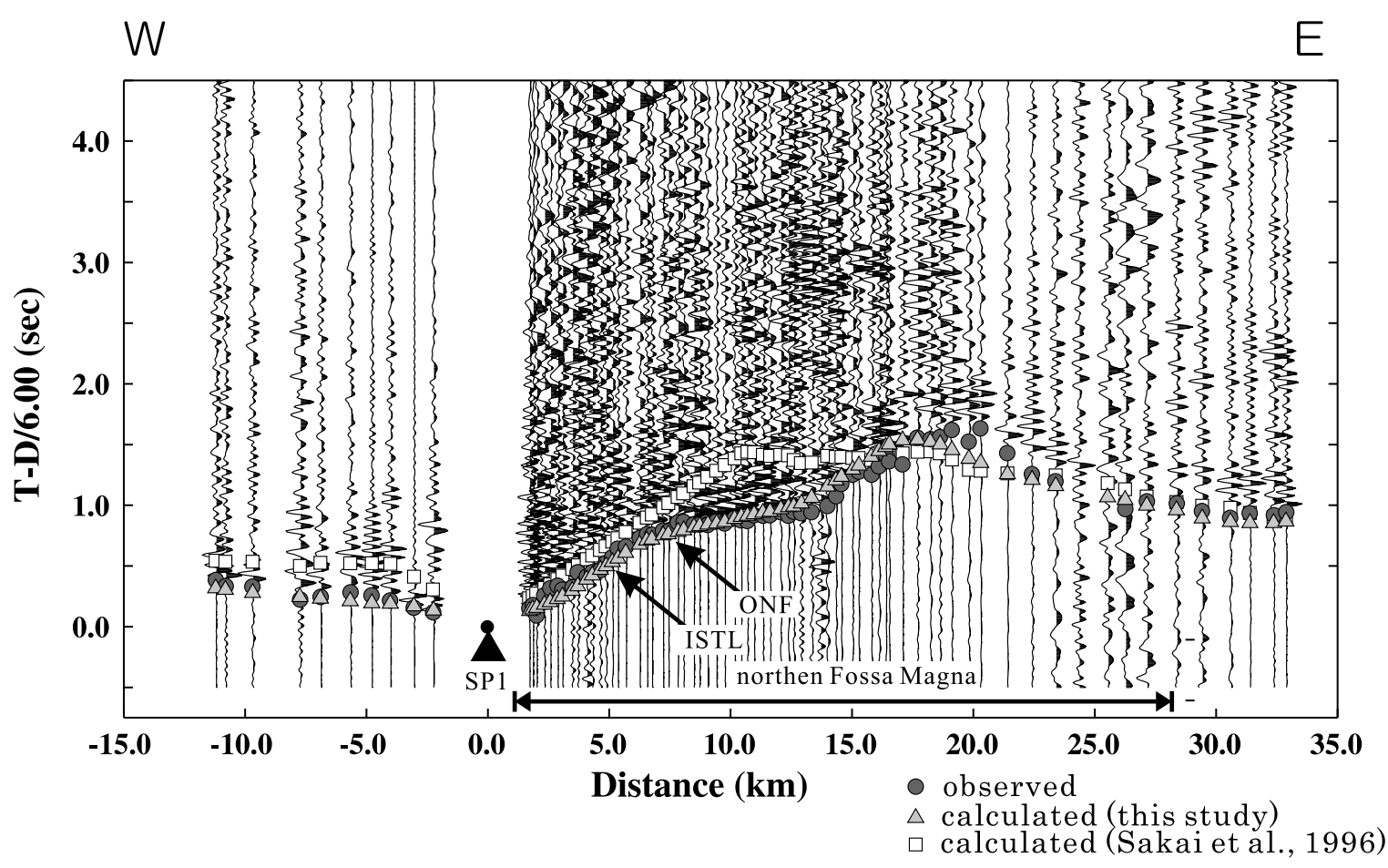

Fig. 4. An example of record section (SP1). The observed and calculated travel-times are superimposed on the record section.

mic attenuation zone below the Hida Mountains. We notice that thick sediments $(>3 \mathrm{~km})$ cover both sides of the ISTL. The total thickness of the west sediments, which has $3.7-4.0 \mathrm{~km} / \mathrm{sec}$ (but the upper limit of velocity is assumed), exceeds $5 \mathrm{~km}$. As in the case of the 1967B, the CUB is characterized by $4.7-5.0 \mathrm{~km} / \mathrm{sec}$ layer of Neogene volcanic rocks and a convex body $(5.95-6.0 \mathrm{~km} / \mathrm{sec})$ underlying just below. The deeper part of the ISTL showed east dipping as well as the shallow part. However, it is noted that a major structural boundary on the surface is not the ISTL, but the ONF. The ISTL and ONF are assumed to be merged together at 1-km depth from the previous reflection section (Sato and Hirata, 1998), and the deeper extension is estimated to extend to at least $4-\mathrm{km}$ depth. In contrast, the WNB is a west dipping reverse fault. In the deeper part below the NFM, a low velocity zone is needed to explain a large delay of travel-time. Actually, all rays passing beneath the NFM have delayed, therefore, the origin of the travel-time delay must extend to the deep part. It is difficult to uniquely determine the structure of the low velocity zone only from our data, because there is a trade-off between width and velocity. Therefore, the velocity is estimated to be less than $5.5 \mathrm{~km} / \mathrm{sec}$ by assuming the width to be less than $10 \mathrm{~km}$ that is a detectable minimum width. The foot depth, however, must be more than $9 \mathrm{~km}$ regardless of the assumed width. Between S-3 and S-4, this profile crosses the northern extensional part of the Takashozu fault, which is an east dipping fault with a slip rate of $0.2 \sim 0.5 \mathrm{~mm} / \mathrm{year}$ (Research Group for Active Faults of Japan, 1991). Although a distinct fault trace around the cross point has not been identified, our model successfully detected an east dipping reverse fault with a $1 \mathrm{~km}$ vertical gap. This indicates a possibility that the Takashozu fault extends northward as a blind fault.
In the $1967 \mathrm{~A}$ and 1981 profile (Fig. 3(c)), the ray paths uniformly cover almost all of the area above a depth of $12 \mathrm{~km}$. The deeper part of the ISTL extends downward to at least $4 \mathrm{~km}$ in depth as an east dipping reverse fault, which is also shown in the 1991 and 2002 profile. The sedimentary layer $(3.5-4.0 \mathrm{~km} / \mathrm{sec})$ at the east of the ISTL is $2 \mathrm{~km}$ thick. It is thinner than that in the 1991 and 2002 profile. Along the CUB, the layer with a velocity of 4.7$5.0 \mathrm{~km} / \mathrm{sec}$ is located near the subsurface. The basement rocks below this layer have a velocity of $5.95-6.0 \mathrm{~km} / \mathrm{sec}$, which is slightly higher than that in the southwest part of this profile $(5.85-5.9 \mathrm{~km} / \mathrm{sec})$. The sedimentary layer at the west, whose velocity is $3.5-4.0 \mathrm{~km} / \mathrm{sec}$ (but the upper limit of velocity is assumed), extends downward to a depth of at least $4 \mathrm{~km}$.

Our results clearly indicate that the ISTL is an east dipping reverse fault as shown by the previous reflection studies, while the WNB is a northwest dipping reverse fault. The Tertiary sediments in the NFM region is very thick, and its thickness increases northward. A thick sedimentary layer to the west of the ISTL lies under the CUB basement rocks at a depth of $4 \sim 5 \mathrm{~km}$. The CUB is characterized by a thin surface layer, the 1-km-thick Neogene volcanic rocks $(4.7-5.0 \mathrm{~km} / \mathrm{sec})$, and basement rocks (5.9-6.0 $\mathrm{km} / \mathrm{sec}$ ). The basement rocks below the CUB have a NESW trending horst structure, whose width is about $30 \mathrm{~km}$ and vertical gap is $4 \mathrm{~km}$ from the surroundings. In Figs. 2(b) and 2(c), we recognize that a wedge structure of the basement rocks cuts into the thick Tertiary sediments.

\section{Discussion}

\subsection{Comparison to previous velocity models}

The previous velocity models by Asano et al. (1969b), Sakai et al. (1996) and Ikami et al. (1986) are shown in 


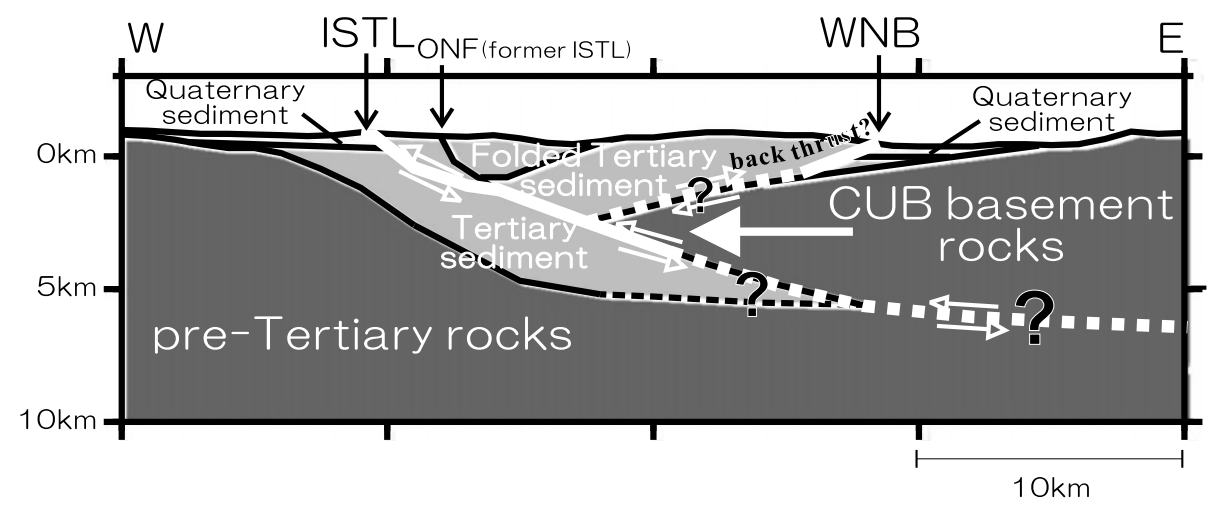

Fig. 5. A schematic diagram of the tectonics in the northern Fossa Magna. The CUB basement rocks, which forms a wedge structure, moves up westward along the ISTL.

Fig. 2, and are scaled to the same size as our models in Fig. 3. The general structural features in the previous models are similar to our models; however, there is a significant change in detail. Our careful analysis strongly indicates the reverse fault structure of the ISTL from our travel-time data. In fact, a reverse fault structure is previously modeled in also Fig. 2(c); however, it is modeled only from gravity data, and cannot explain well the travel-time data. In previous studies, the travel-time calculating methods or the model parameterization had constraints that did not allow for complicated structure including a reverse fault structure. On the other hand, our computational method satisfactorily explained travel-time behaviors due to a reverse fault structure, and correctly modeled the ISTL, the WNB and the Takashozu fault as a reverse fault.

In Fig. 3(b), the NFM structure is clarified and presented in more detail than it is in Fig. 2(b). The travel-times (square) calculated from the velocity model of Sakai et al. (1996) are shown in Fig. 4. The remarkable inconformity is obviously identified between the calculated and observed travel-times in a range of $0-15 \mathrm{~km}$ in distance, meanwhile, the travel-times (triangle) calculated from our model are good consistent with the observed. It suggested that adding the 2002 data contributed to a dramatic improvement of the resolution in the NFM region. Furthermore, the surface velocity of the Hida Mountains is well estimated in combination with geologic information.

\subsection{Seismicity}

The micro-earthquake distribution in 1998-2003 provided by Japan Meteorological Agency (JMA) is superimposed in Fig. 3. It shows that most micro-earthquakes are located within an area in which the velocity is more than $4 \mathrm{~km} / \mathrm{sec}$, and are not distributed within the sedimentary layers $(<4 \mathrm{~km} / \mathrm{sec})$, which is indicated also by the detailed micro-earthquake distribution relocated using our velocity models (Sakai, 2004). However, we recognize exceptional seismicity within the thick sediments (Fig. 3(a)). The exceptional seismicity seems to relate to the volcanic activity, because the seismicity is located below a Quaternary volcano. The adjacent low velocity body might also have resulted from volcanism.

Seismic activity does not form a fault plane as expected from the ISTL modeled. Sakai (2004) showed that most of the micro-earthquakes mainly strike-slip type in the NFM region, and the fault plains expected from the mechanisms are inconsistent with that of the previous large earthquakes. These findings suggest that the fault plane of the ISTL might be kept locked (strongly coupled) during interseismic stage following the last event.

\subsection{Tectonic model}

The models obtained from our data sets show that the ISTL dips eastward, while the WNB dips northwestward. The basement rocks below the CUB uplifts about $4 \mathrm{~km}$ from the surrounding areas. We recognize that the CUB basement rocks form a wedge structure beneath the thick Tertiary sediments at its west side (Figs. 3(b) and 3(c)). This suggests that the CUB wedge moves westward along the deep extension part of the ISTL as an episodic reverse faulting. Based on these descriptions, we propose a present tectonic model, whose schematic diagram is shown in Fig. 5. Our models derived from reanalysis of refraction/widereflection data are consistent with the inversion tectonics model by Sato et al. (2004), which the previous velocity models could not explain sufficiently because of low resolution.

As inferred from this tectonic model, it is possible that the WNB was formed as a back thrust due to the westward movement of the CUB wedge. But the Zenkoji earthquake (M7.4 in 1847) on the WNB requires a fault size of about $3000 \mathrm{~km}^{2}$. Our models cannot explain such a large fault because the bottom of the WNB is no more than $5 \mathrm{~km}$ in detph. Therefore, we suggest that the WNB was originally formed as a back thrust, and a subsequent activation of the WNB made its size larger extending deeper into the crust. Togo et al. (1996) suggested that the northern end of the ISTL has become inactive progressively southward with time. By assuming that a regional compressional stress field has kept a constant strain rate, it is reasonable that such an inactivation of the ISTL should cause a strain concentration and fault activation in another area. Therefore, the main fault activity might have changed from the ISTL to the WNB, which consequently might have been activated and extended to the deeper part.

Though the ONF has already become inactive, the major structural boundary is situated at the ONF rather than at the ISTL, as shown in Fig. 3(b). Ikeda (1983) suggested that a 
thrust-front migration, from the ONF to the present ISTL, occurred in the early Quaternary. This means that the ONF had been active for longer term than the ISTL. It follows that the difference of two structural characters would result from that of their active term.

\section{Conclusions}

We were able to construct detailed and consistent velocity models in the NFM by reanalyzing the refraction/wideangle reflection data. We demonstrated that it was a very effective modeling procedure to combine reflection data and geologic information with refraction/wide-angle reflection data. The structure models obtained revealed the fault geometry of the ISTL and the WNB, and showed a wedge structure beneath the CUB. The wedge structure suggested the westward movements of the CUB basement rocks.

However, several problems are kept unsolved. Why most of micro-earthquakes in the NFM region are strike-slip type? What is a mechanism that the WNB can cause such a large earthquake (>M7)? Our tectonic model could not clearly answer these questions. Therefore, we need to construct a further comprehensive tectonic model.

Acknowledgments. We are deeply grateful to an editor, Professor Y. Ogawa of the Volcanic Fluid Research Center at the Tokyo Institute of Technology, for his helpful comments and suggestions. We would like to thank two reviewers, Dr. S. Onizawa of the Volcanic Fluid Research Center at the Tokyo Institute of Technology, and an anonymous reviewer, for their critical and constructive comments. The 1967A and B, the 1981 and the 1991 profile data were provided by the Research Group for Explosion Seismology (RGES). The hypocenter data were provided by Japan Meteorological Agency (JMA). We would also like to thank Yoichiro Ichinose, Mamoru Saka, Shin'ichi Hashimoto, Toshio Haneda, and Masaru Kobayashi for their efforts toward data acquisition in the 2002 profile.

\section{References}

Asano, S., K. Ichikawa, H. Okada, S. Kubota, H. Suzuki, M. Nogoshi, H. Watanabe, K. Seya, K. Noritomi, and K. Tazime, Explosion seismic observations in the Matsushiro earthquake swarm area, Spec. Rep. Geol. Survey of Japan, 5, Part I, 1-162, 1969a.

Asano, S., S. Kubota, H. Okada, M. Nogoshi, H. Suzuki, K. Ichikawa, and $\mathrm{H}$. Watanabe, Underground structure in the Matsushiro earthquake swarm area as derived from explosion seismic data, Spec. Rep. Geol. Survey of Japan, 5, Part II, 163-201, 1969b.

Geological Survey of Japan, AIST, Geological Maps of Japan 1:200,000 (Images) Version 2.0, Geological Survey of Japan, AIST, 2002.

Hattori, Y. and T. Sugimoto, A statistical study on the longitudinal wave velocities for various rocks in Japan (I), Butsuri-Tanko, 28, 3-12, 1975a (in Japanese with English abstract).

Hattori, Y. and T. Sugimoto, A statistical study on the longitudinal wave velocities for various rocks in Japan (II), Butsuri-Tanko, 28, 43-56, 1975b (in Japanese with English abstract).

Ikami, A., T. Yoshii, S. Kubota, Y. Sasaki, A. Hasemi, T. Moriya, H. Miyamachi, R. S. Matsu'ura, and K. Wada, A seismic-refraction profile in and around Nagano prefecture, central Japan, J. Phys. Earth, 34, 457474, 1986.
Ikeda, Y., Thrust-front migration and its mechanism: Evolution of intraplate thrust fault systems, Bull. Dept. Geogr., Univ. Tokyo, 18, 49-63, 1983.

Ikeda, Y., T. Imaizumi, M. Togo, K. Hirakawa, T. Miyauchi, and H. Sato (eds.), Atlas of Quanternary Thrust Faults in Japan, 254 pp., Univ. of Tokyo Press, Tokyo, 2002.

Ikeda, Y., T. Iwasaki, H. Sato, N. Matsuta, and T. Kozawa, Seismic reflection profiling across the Itoigawa-Shizuoka Tectonic Line at Matsumoto, Central Japan, Earth Planets Space, 56, this issue, 1317-1323, 2004.

Japan Meteorological Agency, Report on the Matsushiro earthquake swarm, Technical Report of the Japan Meteorological Agency, 556 pp., the Japan Meteorological Agency, Tokyo, 1968 (in Japanese).

Matsubara, M., N. Hirata, S. Sakai, and I. Kawasaki, A low velocity zone beneath the Hida Mountains derived from dense array observation and tomographic method, Earth Planets Space, 52, 143-154, 2000.

Nakamura, K., Inversion tectonics and its structural expression, Struct. Geol., 38, 3-45, 1992 (in Japanese with English abstract).

Ogawa, Y., S. Takakura, and Y. Honkura, Resistivity structure across Itoigawa-Shizuoka tectonic line and its implications for concentrated deformation, Earth Planets Space, 54, 1115-1120, 2002.

Research Group for Active Faults of Japan, Active Faults in Japan, revised edition, 437 pp., University of Tokyo Press, Tokyo, 1991 (in Japanese).

Research Group for Explosion Seismology, Explosion seismic observation in and around Nagano prefecture, central Japan, Bull. Earthq. Res. Inst., 60, 615-637, 1985 (in Japanese with English abstract).

Research Group for Explosion Seismology, Seismic refraction experiment in central Japan; Agatsuma-Kanazawa profile, Bull. Earthq. Res. Inst., 69, 139-158, 1994 (in Japanese with English abstract).

Sagiya, T., T. Nishimura, Y. Iio, and T. Tada, Crustal deformation around the northern and central Itoigawa-Shizuoka Tectonic Line, Earth Planets Space, 54, 1059-1063, 2002.

Sakai, S., Seismicity of the northern part of the Itoigawa-Shizuoka Tectonic Line, Earth Planets Space, 56, this issue, 1281-1285, 2004.

Sakai, S., T. Iwasaki, T. Iidaka, T. Yoshii, F. Yamazaki, and T. Kuwayama, The structure of the crust of the Chubu region obtained from explosion observations, Chikyu Monthly, 18, 104-108, 1996 (in Japanese).

Sato, H. and N. Hirata, Deep structure of active faults and evolution of the Japanese islands, Kagaku, 68, 63-71, 1998 (in Japanese).

Sato, H., T. Iwasaki, S. Kawasaki, Y. Ikeda, N. Matsuta, T. Takeda, N. Hirata, and T. Kawanaka, Formation and shortening deformation of a back-arc rift basin revealed by deep seismic profiling, central Japan, Tectonophysics, 388, 47-58, 2004.

Takeda, T., T. Iwasaki, H. Sato, S. Sakai, and T. Iidaka, Crustal structure around the northern part of the Itoigawa-Shizuoka Tectonic Line (ISTL), central Japan, from refraction/wide-angle reflection data, IUGG 2003 Scientific Program and Abstracts, SS03/07A/A02-008, 2003.

Togo, M., Y. Ikeda, T. Imaizumi, and H. Sato, Fault morphology of both ends of the Kamishiro fault along the Itoigawa-Shizuoka Tectonic Line, central Japan, Active Fault Res., 15, 9-16, 1996 (in Japanese with English abstract).

Usami, T., Study of historical earthquakes in Japan, Bull. Earthq. Res. Inst., 54, 299-439, 1979.

Vidale, J. E., Finite-difference calculation of travel times in 3 dimensions, Geophysics, 55, 521-526, 1990.

Yano, T., Late Cenozoic geohistory in the northern Fossa Magna region, central Japan, J. Sci. Hiroshima Univ. Ser. C, 9, 81-132, 1989.

Zelt, C. A. and P. J. Barton, Three-dimensional seismic refraction tomography: A comparison of two methods applied to data from the Faeroe Basin, J. Geophys. Res., 103, 7187-7210, 1998.

T. Takeda (e-mail: takeda@ni.aist.go.jp), H. Sato, T. Iwasaki, N. Matsuta, S. Sakai, T. Iidaka, and A. Kato 